\title{
The (re)production of climbing space: bodies, gestures, texts
}

cultural geographies, DOI: 10.1177/1474474016649399

Jillian M. Rickly

The University of Nottingham

Nottingham University Business School

Jillian.Rickly@nottingham.ac.uk

\begin{abstract}
According to Lefebvre, space is not an absolute given, an empty and presumed starting point, but space is produced through human action. Further, he contends, there is a material basis to the production of space - the "practical and fleshy body". The body must be conceived as both active in the production of space, as well as produced by space, and thereby subject to the determinants of that space. This paper demonstrates the crucial role of the body in Lefebvre's trialectic as it interrogates the embodied mobile practice of rock climbing, specifically sport climbing. First, it begins with an examination of the role of climbing bodies in the production of climbing space; put into practice by the perceived space of the rock, bodies shape and are shaped by this interaction. Second, it investigates the mechanisms that continue the production of climbing space off the rock face, as climbers communicate with practice-specific gestures and jargon. Third, it approaches climbing landscapes as texts, focusing on the production of representations of space as routes are inscribed on rock faces, transcribed into guidebooks and websites, and circulated among climbing media. Finally, considering landscape as a way of seeing forces the investigation to return, full-circle, to situate the ways bodies enact landscapes in relation to textual representations of space. As such, this paper explores the relationality of individual climbing bodies, rock climbing communities, and climbing media in the (re)production of climbing space to demonstrate the complementarity of landscape-body and landscape-as-text perspectives in the social production of space.
\end{abstract}

\section{Keywords}

Rock climbing, Lefebvre, embodiment, gestures, text 


\section{Introduction}

The body takes its revenge - or at least calls for revenge - for example, in leisure spaces. It seeks to make itself known, to gain recognition, as "generative". - Henri Lefebvre

Recent work concerning embodied mobile practices, in particular skateboarding ${ }^{2}$, cycling ${ }^{3}$, walking ${ }^{4}$, parkour $^{5}$, and even rock climbing ${ }^{6}$ illustrates a trend in geography. Since the 1990s, geographers have grown increasingly interested in the role of the body in actively shaping space, as well as shaped by space. Focusing on the embodied mobile practice of rock climbing, specifically sport climbing, this paper employs the theories of Henri Lefebvre to consider the multiple ways in which the body is engaged in the social production of climbing space, from bodily practice to gestural systems of communication to the ideological reproduction and enactment of climbing spaces. It aims to interlace more recent work that foregrounds the role of the body and non-representational perspectives on landscape-body interactions with the landscape-as-text approach that focuses on landscape as doing work, communicating, and wielding power. As an embodied mobile practice, rock climbing demonstrates the complementarity of these approaches to the study of the production of space.

Historically, rock climbing can trace its roots to the earliest mountaineering expeditions of continental Europe, and in particular, the first ascent of Mount Blanc in $1786^{7}$, which subsequently led to the establishment of the first alpine clubs. By the mid-1800s most of the "virgin" peaks of Europe had been "conquered", and adventurers moved on to claim first ascents of specific mountain faces, ridges, and secondary peaks ${ }^{8}$. Rock climbing began to be defined, not without contestation, as "a game focused on a very definite achievement: the ascent, in specified style, of specific routes on a cliff" ${ }^{\circ}$. The most important aspects of this definition are the omission of a summit and its emphasis on the "route".

In the last century, rock climbing has witnessed a tremendous diversification of styles and approaches. One of the fundamental divides in rock climbing is between aid climbing and free climbing. Whereas free 
climbing means only hand and feet are used to propel the climber up the route (the rope, harness, and other gear are used only as protection in case of a fall), aid climbing places gear (stirrups, ladders, slings) by which the climber ascends the rock face. Free climbing is further divided by several styles - traditional climbing, sport climbing, and bouldering, most prominently. In traditional climbing temporary protective gear (cams and nuts) are placed in natural rock features (usually cracks) by the lead climber and removed as the second climber ascends. This style of climbing emphasizes adventure, danger, and risk management ${ }^{10}$. Sport climbing developed in areas where, because of the type of rock or overhanging cliff lines, traditional climbing was not possible ${ }^{11}$. So, as opposed to traditional climbing, it utilizes permanently placed protection, usually bolts that have been drilled into the rock. As a result, sport climbing requires less equipment, but this also produces a different style of movement and engagement with the rock face; sport climbers are more focused on endurance, strength, and gymnastic ability ${ }^{12}$. Bouldering, then, takes place within a shorter distance (less than $20 \mathrm{ft}$.) from the ground so that no ropes are used, just a "spotter" (a climbing partner) who directs one's fall towards "crash pads" for landing. With its minimal use of gear over short routes (referred to as "problems"), bouldering emphasizes agility and power ${ }^{13}$. Such distinctions are important as this paper focuses primarily on sport climbing; although, many of the ideas are generalizable to other styles.

Rock climbing has garnered considerable attention within leisure studies ${ }^{14}$, environmental psychology ${ }^{15}$, and sports medicine ${ }^{16}$. In geography, specifically, this bodily practice has fallen under two distinct areas of research - landscape-as-text and landscape-body relations. From the field of historical geography, utilizing a landscape-as-text approach, investigations of rock climbing have focused on the social processes of rock climbing, particularly the shaping of landscapes for the act of climbing, contestations surrounding the development of guidebooks, and masculinist perspectives on nature ${ }^{17}$. Research that concerns landscape-body relations of rock climbing, however, has foregrounded the climbing body and non-human agency while engaging actor-network theory and non-representational theory ${ }^{18}$. This paper works across and weaves together both of these approaches to rock climbing by using Lefebvre's theories 
of the production of space. In so doing, it demonstrates that scholarship on embodied mobile practices should not be bifurcated into text-based and agency-oriented studies, but these various approaches are most productive when they can be melded so as to examine the relationality of bodies and texts, emotions and technologies, action and cognition. The paper begins with an examination of the role of climbing bodies in the production of climbing space - spatial practice produces the space of the body, itself shaped through this practice. Through the use of gestures (more-than-representational), the spatial practice of climbing is connected to representational spaces (imagined spaces) and representations of space (codes and signs of climbing) that continue the production of space off the rock face. Furthering the investigation of the production of representations of climbing space necessitates a consideration of climbing landscapes as texts - written upon through bolts and chalk, written about in guidebooks and other climbing media, and spoken of with climbing-specific jargon. Yet, the production of climbing space does not end here. These representations of climbing space become doings when employed in the climbing community as measures of ability and when they inform the perceived space of the rock face, influencing the spatial practice of climbing. Thus, considering landscape as a way of seeing complements the embodiment of the spatial practice of climbing by situating representations of space in the enactment of climbing landscapes and the reproduction of climbing ideologies.

In order to approach the multiple ways in which social and bodily practices produce climbing space, the work of Lefebvre is of import. According to Lefebvre, space is not an absolute given, an empty and presumed starting point, but space is produced through human action. Further, he contends, there is a material basis to the production of space - the "practical and fleshy body"19. The body must be conceived as both active in the production of space as well as produced by space, and as a result, subject to the determinants of $\operatorname{space}^{20}$. So while other theorists, namely Pierre Bourdieu, Erving Goffman, and Michel Foucault are, perhaps, more frequently associated with studies of performativity, embodied practice, and ideology, it is argued that the inherent spatiality of Lefebvre's theories offer a means to bring these aspects together under a single framework ${ }^{21}$. Indeed, more recent scholarship has demonstrated the 
potential of reconsidering Lefebvre's writings, particularly in regards to the role of the body. Simonsen ${ }^{22}$ suggests that because of the duality of the body - as producer and produced by space - Lefebvre's theories work across two major debates in geography - body politics and performativity. In terms of politics, the body "as a producer of difference (through rhythms, gestures, imagination), has an inherent right to difference", yet the body as shaped by spatial practice also attends to notions of performativity and embodiment ${ }^{23}$. Because of their holistic perspective on the spatial body, Lefebvre's theories are particularly well-suited to traverse the various academic approaches to rock climbing. In so doing, his theoretical framework for the production of space facilitates an analysis of the ways in which bodily practice, perception, communication, and representation inform one another in relational rather than linear ways.

\section{Research context and positionality}

This paper is primarily based on the numerous informal observations and conversations that have resulted from the my long-term relationship with the rock climbing community, generally, as well as drawing on grounded fieldwork with climbing community the Red River Gorge, Kentucky, USA, specifically. In terms of positionality, while I do not rock climb, I have a personal relationship with the climbing community - concentrated in the Midwest of the US (and particularly southern Indiana and eastern Kentucky) - that dates 16 years. From being introduced to the sport through acquaintances and dabbling in the practice myself for a brief time to developing long standing friendships with climbers (and a partnership), which resulted in many day and weekend trips to climbing areas and innumerable hours spent reading climbing magazines and watching climbing films, an intimate understanding of the climbing community, generally, (and specifically in regards to the Midwest) has been developed. As a result, my interactions with climbers span skill levels and degrees of dedication to the sport that include hobbyists, novice and expert climbers, lifestyle climbers ${ }^{24}$, and sponsored climbers. 
In-depth analysis of the climbing community in the Red River Gorge, situated in the foothills of the Appalachian Mountains in eastern Kentucky, further supports and refines my understanding of the ways popular climbing destinations are situated in larger networks of climbing mobilities. These mobilities are not limited to climbers traveling for rock climbing, but such destinations develop reputations, referred to as "scenes", that circulate across climbing media (magazines, websites, and films). Indeed, climbing destinations have unique place identities that relate to geology and how that translates to predominant climbing styles (aid, traditional, sport, bouldering, etc.), ${ }^{25}$ as well as to the sociality of these places and their cultural nuances. The film Red River Ruckus illustrates this ${ }^{26}$. In addition, throughout this research, popular climbing websites, specifically rockclimbing.com and redriverclimbing.com, were investigated and data collected from online forums were used to inform many observational cues and interview questions. While climbers do meet and perform group identities on the ground, in specific locations, the online forums foster community exchanges and reveal fractures and tension.

In 2011 (August through November), I conducted a grounded ethnography in The Red that included participant observation, interviews, and surveys aimed at investigating the roles of hypermobility and lifestyle travel in the pursuit of rock climbing. In total, 21 lifestyle climbers were interviewed -6 females and 15 males. The age of participants ranged from 22 to 56 years, and mobility varied such that time spent travelling for full-time climbing extended from just six months to 17 years. Interviewees were predominantly white ${ }^{27}$. All but two interviewees were Americans, with the exception of one Canadian and one person from France, and two respondents self-identified as gay and lesbian, respectively.

It is important to note that the trialectic analysis of this paper is focused on the (re)production of outdoor climbing spaces through the embodied act of climbing, communication of this practice through jargon and gestures, circulation of ideologies through the representations of climbing space, and (re)production of such spaces that feedback into and upon one another. The foregrounding of outdoor climbing space, however, is not intended to ignore or exclude indoor climbing spaces or the growth of urban climbing. 
These settings further illustrate the power of co-production, especially in the ways indoor climbing gyms conceive of climbing space and aim to reproduce the feel of rock, and simultaneously the climbing body $^{28}$, and how urban climbing subversively re-imagines human-made structures (perceived spaces) as appropriate for the spatial practice of climbing. Rather, this paper merely begins a conversation that demonstrates Lefebvre's triad in work but does not presuppose to place boundaries around its effects/affects.

\section{The production of climbing space}

According to Lefebvre, social space is a triad of spatial practice, representations of space, and representational space. It is through spatial practice that a society produces its space. Through practices that embrace production and reproduction, characteristic of each social formation, a specific level of performance embodies a close association with perceived space ${ }^{29}$. Lefebvre thus states, "From an analytical standpoint, the spatial practice of a society is revealed through the deciphering of its space" 30 . Representations of space are related to production and notions of order imposed upon social space. As conceived space, representations of space are the work of scientists, planners, engineers, some artists, and those "whom identify what is lived and what is perceived with what is conceived" 31 . Thus representations of space are associated with systems of signs and codes. Representational space may too be associated with complex symbolisms and codes, but unlike representations of space, these tend to be non-verbal and non-textual signs. Representational space is lived through imaginative renderings, it "overlays physical space, making symbolic use of its objects" ${ }^{\prime 32}$. While each aspect of social space may be isolated through analysis, the triad works together. Simonsen ${ }^{33}$ explains that in order to understand the production of space, we must comprehend the concrete (perceived space) and the abstract (conceived space) together "we need a dialectic relation between materialism and idealism. This is where the notion of the lived [representational space] comes in - as a third term between the poles of perception and conception. Socially lived space depends on material as well as mental constructs - and on the body." 
While a Marxist philosopher, Lefebvre found shortcomings with Marx's concept of social practice as it inadequately accounts for the body, subjectivity, and desire. As a result, he also engaged the work of existentialists and phenomenologists to better articulate the relations of the body to social practice.

Simonsen $^{34}$ notes that Lefebvre's work is of particular significance in this regard as it elucidates the space of the body, that is, it reinvests the "spatial body" in philosophy that, by focusing instead on the "body-inspace", had witnessed a decorporealization. Indeed, Lefebvre argues the triad of social space - perceived, conceived, and lived (in spatial terms: spatial practice, representations of space, representational spaces) loses all applicable force if it considered in only abstract terms, as such the body must also be appropriated into this model. Social practice presupposes the use of the body, asserts Lefebvre. The use of hands, arms, feet, sensory organs, and so on, not to mention gestures, are spatial practices of the body. Even before such appendages and bodily members are put to work in the material realm, with tools and objects, "there is an immediate relationship between the body and its space, between the body's deployment in space and its occupation of space"35 - a quote that illustrates the influence of Heidegger's writing on Lefebvre's thinking. Thus, it is the body that holds the spatial triad together.

An investigation of the production of climbing space, then, can hardly be achieved without attention to the role of the body. As such, one of the goals of this paper is to demonstrate the crucial role of the body in Lefebvre's trialectic formulation through an example of embodied mobile practice. In terms of spatial practice, it is the bodily performance (individual and collective bodies) of the rock face that produces and reproduces climbing space. In so doing, climbing bodies are also subject to the determinants of this space, shaped by the spatial practice of rock climbing. Yet, climbing bodies continue the performance of climbing space off of the rock face through the use of gestural systems, which communicate representational spaces of climbing among the climbing community, as well as foster representations of space. Further, representations of climbing space are produced in the development of routes, the publication of guidebooks and websites, as well as magazines, films, and other climbing media and the use climbing jargon. Such conceptualizations of space thereby inform the climbing body, affecting the 
perceived space of climbing, and thus become enacted representations that can perpetuate or challenge climbing ideologies.

\section{Climbing bodies as producer and produced}

Human bodies are spatialities of position and situation so that our bodies are not in space/time but inhabit $\mathrm{it}^{36}$. Through bodily performance, space is activated as the current position of the ever-changing world. So while bodies inhabit space, they also produce space. In developing his theory of the social production of space, Lefebvre turned to the work of Heidegger and Merleau-Ponty as a means to account for the body in this process. Merleau-Ponty argued the body should not be viewed as an object, but rather as the "condition and context" of experience ${ }^{37}$. He stated, "The body is the vehicle of being in the world [...] I am conscious of the world through the medium of my body"38. The work of phenomenologists can be seen in the way Lefebvre understands the role of the body in the production of space - as producer and produced. This is well illustrated through the practice of rock climbing.

In his study of rock climbing, Lewis foregrounds the climbing body, arguing that it "physicalizes or embodies a set of ideas and practices that often belie the deep-rooted ambivalence held by modernity towards the body and sensuous knowledges [...] organic, self-determined, tactile, of the ground" ${ }^{39}$. The spatial practice of climbing is a process of embodiment, shaping both the rock and the body. The climbing body produces the climbing space of the rock face, in the form of routes, as hands and feet find the appropriate holds to propel the climber upward. What is but a sublime cliff line and the point of gazing for the non-climbing body becomes an embodied space when climbed. Gazing upon a rock face, routes are seen through trained eyes as perceived space and are enacted through the performance of climbing ${ }^{40}$. Yet climbing is also a defacing - climbers leave residues of chalk, they "clean" the rock face of plants and debris, and they intentionally and accidentally remove bits of rock ${ }^{41}$. However, Rossiter also contends that climbing is an "animated intercorporeality", "climbing bodies must deface and [...] the cliff simultaneously defaces them",42. Similarly, Lewis describes the act of climbing as working upon the body; 
it is "recast, moulded and shaped, transformed" through this embodied practice ${ }^{43}$. Further, Lewis argues climbing is a mapping - the climber maps the rocks with his body and is, in turn, mapped by the rock $^{44}$. As such, Lefebvre's discussion of the material body is applicable in this regard. The climbing body is not derived from the fact that it has the ability to climb, but from its enactment - the spatial practice of climbing, the body's movement on, across, and against rock.

Among theories of the body, Merleau-Ponty and Foucault are often interpreted as dichotomous. Whereas the former emphasizes the body as actively social, generative, and lived, the latter built his theories of the body to demonstrate the ways it is acted upon, constructed, and inscribed socially and historically ${ }^{45}$. Simonsen ${ }^{46}$ contends, however, that Lefebvre's integration of the body into theories of space has the ability to transcend this division. As Lefebvre states:

The materiality of this body is attributable neither to a consolidation of parts of space into an apparatus, nor to a nature unaffected by space which is yet somehow able to distribute itself through space and so occupy it. Rather, the spatial body's material character derives from space, from the energy that is deployed and put to use there. ${ }^{47}$

Attending to the climbing body as both producer and produced, as Lefebvre suggests, illustrates the relationality of the lived body of Merleau-Ponty, the occupation of space as theorized by Heidegger, and the socially inscribed body of Foucault. 


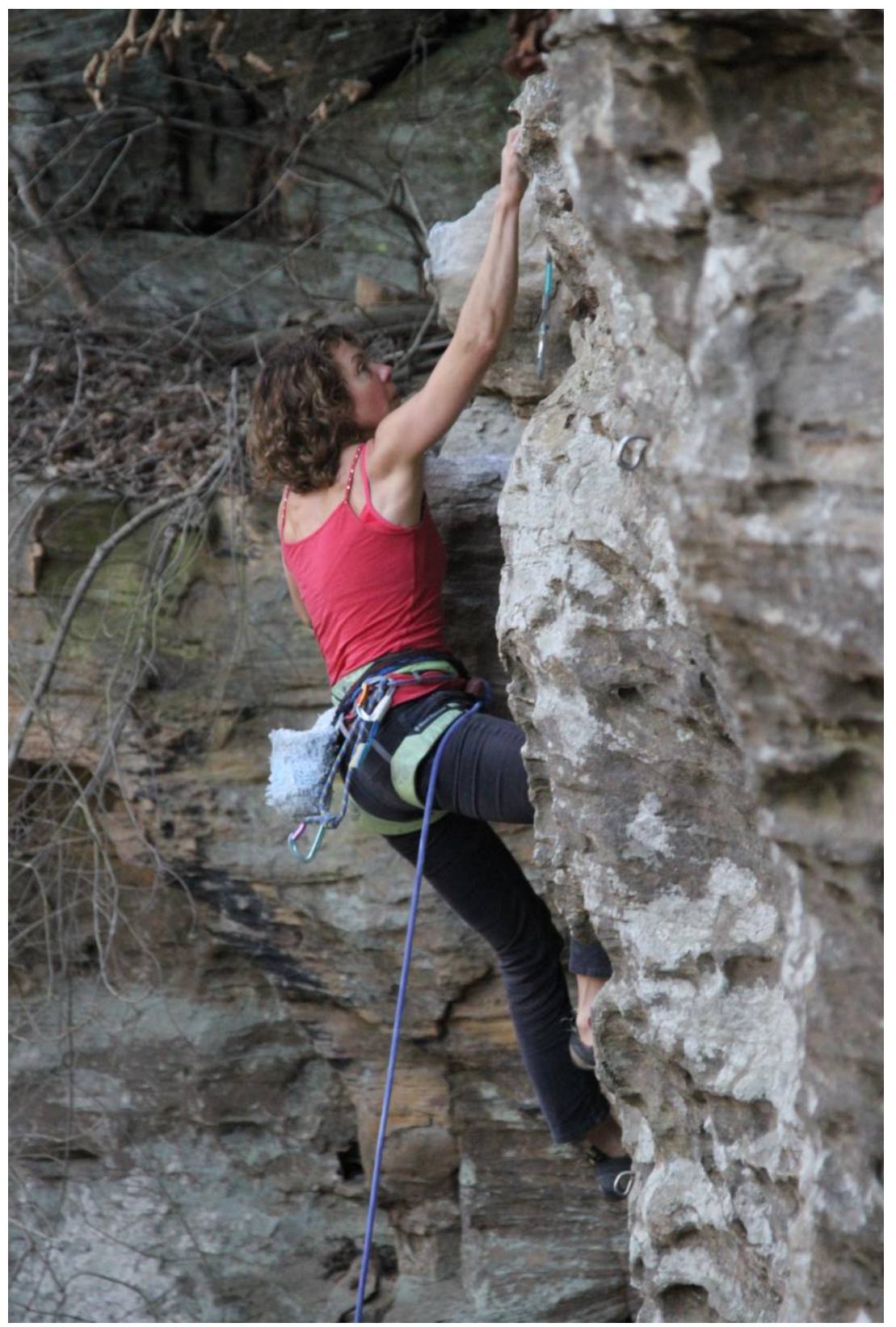

Figure 1 - Rock climbing. Photo courtesy of Bryan Boyd.

Through its spatial practice climbers acquire an intimate, embodied knowledge of the rock face. Routes require a great deal of time and focus to accomplish (or "send"). Thus, one of the greatest differences in the approaches of traditional and sport climbing is in learning the route ${ }^{48}$. Sport climbers describe routes 
they are working to ascend as "projects", and they spend considerable time "working the route". This means the climber will ascend a route until encountering difficulty, a point that s/he cannot climb through, in the form of specific hands and feet placements and body positioning, and as a result falls. This is usually the "crux" of the route. Rather than go back to the ground and climb through the entire route again, s/he will lower to a point just below the difficult sequence, examine the rock face and potential holds and try again. Through "working the route" the climber is evaluating the perceived space of the rock face. In doing this, over time, the climber learns a specific choreography for each route climbed. A choreographic movement the climber can readily recite off the rock face as an embodied knowledge. This embodied spatial knowledge includes where to relax and take a short break to shake out tired arms, positionality on the rock to efficiently clip quickdraw to bolt and the rope to the carabiner, as well as how much energy to exert in specific movements in order to conserve energy for the crux.

Further, the use of this climbing-specific jargon illustrates the social production of climbing space. Jargon extends representations of space from the spatial practice of the rock face and the perceived space of the climbing body to the social spaces in which the climbing community gathers. However, when in the act of climbing, the lived and perceived spaces are foregrounded. Because the climber's visual perspective on the rock face is limited to only a few feet radius around the body, one learns the feel of the holds one is reaching for - a "mono-pocket" (a hole in the rock just large enough for a single finger), a "crimper" (a small, narrow hold which allows only for the ends of one's fingertips to grip the rock), or a "jug" (a large hold that requires the use of the whole hand) - and its relational distance to the spatial body. "Touch is the pivotal sense utilized by climbers in learning to know a climb", contends Lewis, "a corporeal knowing rather than a cognitive knowing" 49.

The climber's interaction with the rock shapes the body, from the practice of climbing as well as forceful encounters with the rock. Muscles are strengthened, particularly in the arms, chest, and core ${ }^{50}$, and skin is scratched, calloused, and scarred, especially on the fingers from grabbing holds and on hands and arms as 
a result of jamming appendages into cracks. Many of the strongest climbers develop "climber's back"; a hunched or slouched posture that results from the overdevelopment of chest and bicep muscles in relation to thorax muscles ${ }^{51}$. Thus, Lewis argues, "the practice of rock climbing cultivates the body towards a better configuration for climbing" ${ }^{52}$. In fact, different styles of rock climbing and approaches to the rock face cultivate differing climbing bodies (see Figure 1). As professional climber Chris Sharma writes:

As I get older, there's one thing I appreciate about sport climbing more than anything: its friendliness on the body. While bouldering is all about holding on as hard as you can to the smallest, most painful holds, sport climbing allows you to breathe and relax. You connect to the rock with as little grip - both mental and physical - as possible in order to conserve your energy. ${ }^{53}$

Notions of energy expenditure are central to Lefebvre's integration of the body into the concept of social practice. In the production of space, it is the energy deployed by the body that produces space and, as such, produces the body. However, as Rossiter ${ }^{54}$ and Barratt ${ }^{55}$ have shown, the act of climbing is more than a human-nature relationship, but includes numerous non-human agents that influence the deployment of energy while climbing. So, while the rock has agency, modifying a set of conditions - that is, offering a set of potentialities with which each climbing body individually engages - materialities that make a difference in the climbing, even make the climb possible in some instances, should not be ignored. Lefebvre suggests objects, utensils, and tools work as extensions of the body. But such materialities do more than extend the body; they alter the lived space and the perceived space of climbing by affecting the way a climber approaches the rock face, in terms of confidence with reliable, tested, and trusted gear or perhaps reticence with inadequate, worn, or new gear. As Barratt argues, the climbing body and its kit function as a hybrid climbing-assemblage enabling the climb to happen ${ }^{56}$.

Returning to Chris Sharma's quote above, which speaks to differing climbing bodies, it also implicitly suggests the role of climbing materialities in the lived space of climbing. Sharma draws the distinction between the lived spaces of bouldering and sport climbing, suggesting the former prioritizes power and pain, the latter connection and breath. While sport climbing employs a rope, harness, carabineers, and 
belay device, which function as safety devices, and bouldering only uses a crash pad, all types of climbing utilize particular rock climbing shoes. Made of sticky rubber, climbing shoes are used to improve grip and traction on the rock face. As such, they are more than extensions of the body; they modify the conditions of the space facilitating ascension of a route. As extensions of the body climbing shoes allow access to holds that require greater adhesion, but they also protect the body (the foot) from the determinants of the climbing space (the jagged rock face). Yet, as Barratt describes, "The ergonomics of climbing shoes are not usually harmonious. Climbing shoes are often chosen that are too tight and painful after prolonged use because climbers find that they climb better in tight shoes." ${ }^{57}$ In this way, the climber's feet are not preserved and protected as they were prior to climbing, but are changed as a result of wearing overly constricting climbing shoes. While they are protected from defacement by the ragged rock, they are nevertheless manipulated by the shoes employed to climb the rock ${ }^{58}$. As with other gear, they also influence the climber's approach to the route. Familiarity with the gear one is using, and understanding its potential and limitations, results in differing perceptions of climbing space, thereby informing specific performances of climbing. Indeed, Barratt's ${ }^{59}$ work on the ice climbing assemblage demonstrates this effect.

Thus, Sharma's quote illustrates the co-production of climbing space. It is not just the materialities of climbing that alter the lived space of the rock face, but perceptions of climbing space influence the role of the body in climbing the space and the climbing kit one puts to use. In other words, the climbing space does not determine the equipment that will be used, but the individual climber's perception and assessment of the space does. As Lefebvre has noted, ideologies do not produce space; they are in space ${ }^{60}$. As a co-production, a climber's assessment is informed as much, if not more so, by the information and "knowledge" (representations of space) acquired off the rock face as it is by the perceived space of the route. The ideologies of the appropriate climbing assemblage, given a particular perceived climbing space, are associations made outside of the body performing climbing. This is further illustrated in the varied responses to professional climber Alex Honnold's " "free soloing" (climbing without protective 
gear) of, most notably, El Capitan in Yosemite National Park in 2012. While some climbers rationalize this endeavor as productively subversive, challenging the status quo, and removing the excess of climbing equipment and rhetoric to be existentially closer to the practice, others see it as simply unnecessary risk that puts the wider community in jeopardy of undue criticism. All in all, the spatial practice of climbing is not homogenous; the representations of climbing space are perpetually challenged on and off the rock face. The production of climbing space is a co-production that extends far beyond the body in practice to more-than-representational gestures, as well as jargon (representations of space) used to communicate in social settings, to the dissemination of climbing ideology through media, each of which also informs climbing practice.

\section{Gestures and more-than-representational communication}

Embodied mobile practices, from walking to driving to playing, are essential to how we experience the world, as they "create spaces and stories - spatial stories"62. Rock climbers" spatial stories produce representational spaces far from the rock face, as they recount entire routes or just sequences of moves to other climbers using climbing-specific jargon (representations of space) and gestures (more-thanrepresentational). Thus, Simonsen suggests gestures are "a spatialized version of Bourdieu's theory of practice and the body's incorporation of history" ${ }^{\prime 3}$. As part of the co-production of space, gestures bind ideology to practice, illustrating the relationality of the spatial practice of climbing to the ways representations of climbing space are circulated and put to use.

Much of a climber's day is actually spent off the rock, but nevertheless immersed in the practice. Conversational topics include what was climbed that day, troubleshooting with fellow climbers regarding difficult sequences, potential new routes to "project" (begin working on), newly discovered cliff lines, future travel plans, and so on. Discussion of routes climbed, in particular, includes recitation of portions or even the entire route, from the starting holds through the crux to the anchors, thereby illustrating the essential elements of narrative - setting, plot, characters, and so on. Witnessing such a narrative display 
between climbers in her fieldwork, Ness explains, "they moved between linguistic and gestural forms of representation with a fluency that indexed their combined extensive practice" ${ }^{64}$. That is, climbers in conversation communicate spatial associations not only through practice-specific jargon, but also require the "more-than-representational" $"$, in the form of non-linguistic sounds and gestures, to convey meaning.
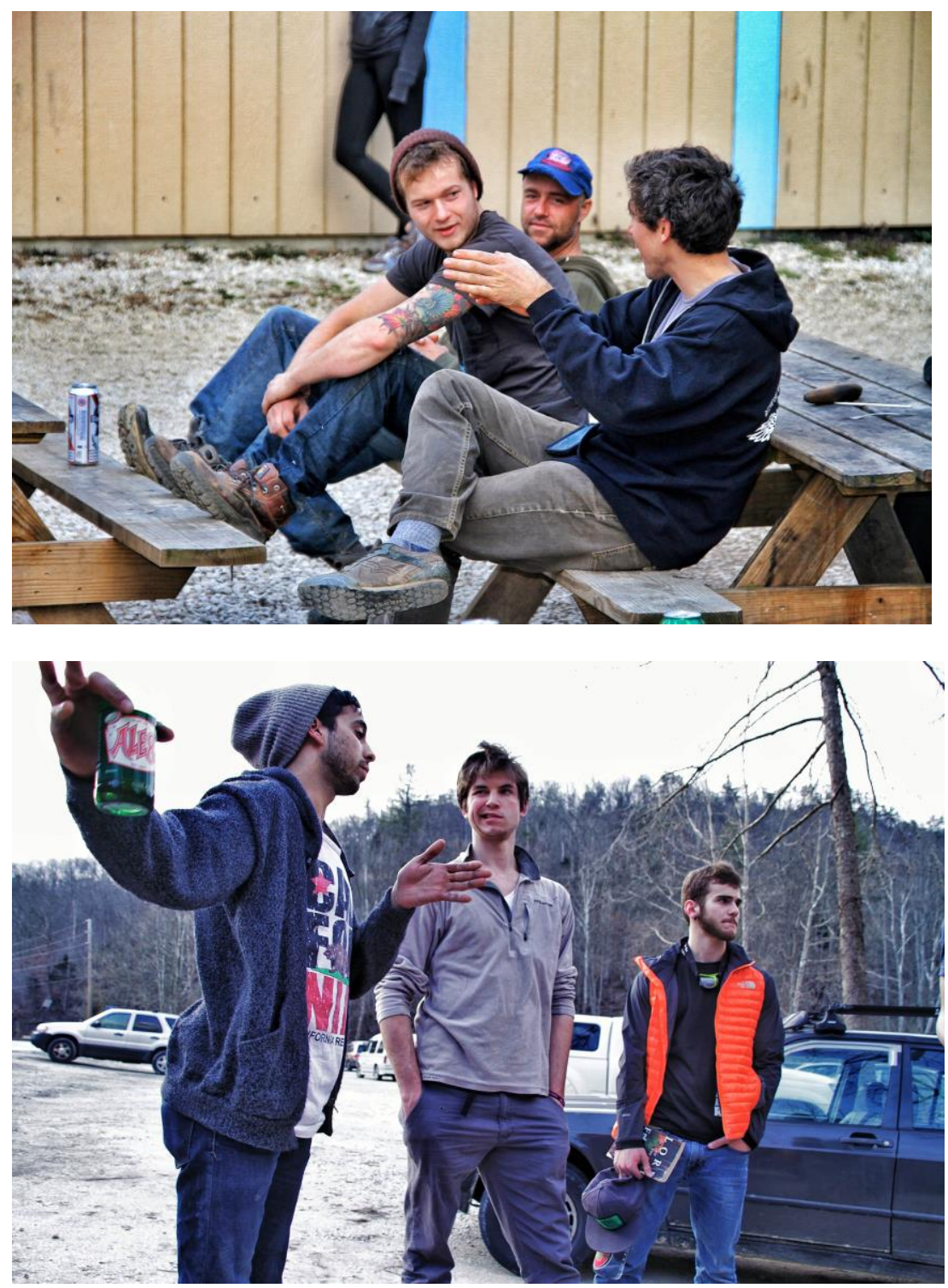

Figure 2 - Gestures. Photo courtesy of Bryan Boyd.

Gesture, in this sense, is taken from the Lefebvrean notion as a means through which the body determines and communicates space. Most broadly, a gesture is a bodily movement "which modifies a person's 
orientation and points of reference. The word is preferable to 'behavior' for a gestural action has a goal or aim (which is not, of course, to imply some immanent teleology)"66. A gesture could be a pointing finger or it may be turning one's head at the sound of a sudden noise, both of which indicate or make reference to an action. As such, gestures are more-than-representational; they communicate beyond the limitations of vocabulary ${ }^{67}$. In the case of climbing narratives, the teller combines verbal descriptions with the physical performance of parts of the routes (See Figure 2). S/he employs gestures in the form of mimicking hand and body movements of the moves described, accompanied by sounds - grunts, gasps, cheers - to indicate the difficulty and style of movement on the rock. In fact, one can glean the types of hand holds that compose the route in the hand formations exhibited - wide open hands for a "jug", a tightfingered gesture for a "crimper", or an outstretched finger for a "mono-pocket". Narrating the route communicates one's intimate knowledge, or "corporeal knowing"68, of the rock face and provides "beta" (helpful information regarding types and locations of holds and body placement to successfully complete the route) to fellow climbers. This is both an imaginative and physical enactment, but also a narrative performance of space requiring performer and audience. As such, narration of the spatial practice of climbing produces a storied space, a representational space, while gestures extend to the more-thanrepresentational. Indeed, Somdahl-Sands ${ }^{69}$ argues this is necessarily so. While on the rock face, in the performance of climbing, the body is engaged with perceived space and as such it acts. Cognition and action cannot take place simultaneously. Cognition either informs movement or makes sense of it after the fact. When the body is in motion, it is in action. In narrating a route, a climber cognizes the spatial practice of climbing, and, in so doing, commits the choreography of the route to memory, producing a representational space.

Gestural systems function as performative language ${ }^{70}$. This is an insight that was developed by Goffman $^{71}$, in particular, who understands the body as a material resource for communication. Social interaction requires more than verbal communication; as such bodily gestures are necessarily employed. Examining the relationship between the production of space and such gestural systems, Lefebvre states, 
"gestures as a whole mobilize and activate the total body", and in so doing they are not simply performed in space, but "bodies themselves generate spaces, which are produced by and for their gestures" 72 . Through gestures the social production of climbing space extends well beyond the rock face to the social spaces where climbers gather and camp. These social spaces are filled with conversations of climbing, conversations that require more than verbal communication to communicate the spatial practice (perceived space) of the route. Words mix with bodily movements and mimicking gestures, from handholds to bodily postures, as well as non-verbal sounds. Gestural systems produce another type of climbing space, a representational space that relates the spatial practice of rock climbing and the morethan-representational lived experience of the route, with the imagined spaces of the listener/viewer of the narration.

Yet, gestural systems also "embody ideology and bind it to practice"; and in so doing, they connect the representational spaces of narration to representations of space $^{73}$. In other words, ideology works not just by influencing one's thoughts, but informing one's actions. As performative language, gestural systems make use of symbols, signs, and signals that denote affiliation. Goffman, writing on this matter, posited that the body, and its employment of gestures, mediates one's self identity and social identity, as gestures function as shared vocabularies. In the case of rock climbing, the use of gestures to accompany descriptive language produces both conceived and lived spaces far from the rock face where the spatial practice takes place. This is a social space in which only those familiar with the embodied, spatial practice of climbing can actively communicate and make use of the information shared in the gestural signal. It is a space associated with signs and codes, the use of which connects these representations of space to the imagined (representational) space of the listener/viewer through the more-than-representational communication of gestures. Through the continual telling of narratives of spatial practice, which employ gestures, they have the power to influence the way other climbers approach respective routes. In this way, gestures further ideology, informing the conceived and perceived spaces of the rock face. 


\section{Landscapes as/in climbing texts}

The work of Nettlefold and Stratford, as well as Taylor, have illustrated that climbing landscapes can be read as texts, not only through scholarly investigations, but they are also presented to climbers in a highly textualized manner ${ }^{74}$. While gestures communicate the embodied practice of climbing, thereby connecting representational spaces to representations of space, climbing spaces are also witness to other social processes that further produce representations of space. These representations of space include climbingspecific jargon and the inscription of routes onto rock faces, as well as guidebooks and other climbing media that transcribe and circulate such representations.

A climber approaching an undeveloped (or "virgin") rock face engages a perceived space of climbing, as the climber considers potential routes and trajectories for ascending its surface. It is, then, through the embodied practice of climbing that the climbing space is physically produced. As such, each climber produces a different climbing space, moving across the rock surface, positioning the body, and attending to holds in ever so individual ways. Yet, climbers rarely encounter and climb undeveloped rock faces. Instead, it is more likely a sport climber will approach a developed route - one in which the rock face has been "cleaned" of vegetation and bolts drilled into its surface with hangers attached (a safety mechanism which climbers clip a carabineer to and through which thread a rope). As such, a route becomes set in the stone. A climber may move according to her/his individual preferences along the rock surface, but s/he returns again and again to the set trajectory of the bolts so as to set a safety measure. As such, a developed route is a conceived space, functioning as a representation of space. Once bolted the climbing space has limits and parameters, directions have been embedded in it. This established path is further delineated the more a route is climbed - the use of chalk highlighting the most popular holds. This representation of climbing space is, in fact, best observed from afar by the non-climbing body. From a distance, the viewer can see pathways emblazoned on the rock face as climbers have again and again repeated its trajectory. Thus, the rock face becomes a text, with routes literally written upon it - first an outline, the bolts offering some structure or signposts suggesting direction, then chalk accumulates on individual holds marking a 
more distinct path. However, the route is not static. As Rossiter explains, climbing is a defacing ${ }^{75}$. The more the route is climbed, with individual hands grasping the same holds again and again, the rock is polished. It changes shape. It is eroded from wear, becoming smoother, resulting in less friction, and thus making the route more difficult to climb. This is rarely inferred from afar when assessing the route as a textual representation of space, but becomes apparent through the spatial practice of climbing. In this way, with the increased frequency of climbing the materiality of the rock is becoming resistant to climbing.

The development of a route also includes the process of naming. While a route may be named in relation to its physical character or setting, it is just as likely to refer to social circumstances of the climbing community or broader social trends ${ }^{76}$. Route names, however, do not appear on the physical rock face, so a climber may approach a route, ascend it, and never be aware of the name (representation of space) placed upon the space. In fact, to learn the name of a route one must consult a guidebook or members of the local climbing community. Thus, route names are another layer of the representation of climbing space, which appears outside of the physical space of climbing, but which do hold currency in the climbing community. Route names are recorded in guidebooks and used in conversation, along with other details imposed upon the climbing space, including its grade, or difficulty rating. Guidebooks, by functioning as a representation of climbing space, are also significant in the process of textualizing the landscape. As summarized by Nettlefold and Stratford:

[Guidebooks] generally provide both maps (or photographs) of a given climbing area and written descriptions of individual routes. A typical route description includes the names of the route (which objectifies and humanizes the appropriated nature feature); a numeric grade (which describes the feature in relation to a quantified difficulty), an associated route description (which relates the appropriated feature to the activity of the climbing), and 'historical' information (which notes when, and by whom, the route was first climbed). ${ }^{77}$

In addition to this description, it should be added that most guidebooks also feature "topos" of crags and cliff lines. These are vertical mappings or graphical representations of routes that include lines drawn on photographs or abstract maps, which are populated with a set of symbols that indicate rock features and 
associated climbing tools. Taylor explains that standardizing this lexicon solved "many of the problems inherent in verbal descriptions" ${ }^{78}$. In other words, the pervasive acceptance and use of these representations of climbing space limited the possible interpretations of the spatial practice.

A landscape as text approach is thus useful for deconstructing the power relations that contribute to the production of representations of climbing space. Examining landscapes as texts turns attention to "reading" landscapes. Indeed, Lefebvre states, "an already produced space can be decoded, can be read", as this implies a process of signification and spatial codes have been produced along with the space ${ }^{79}$. Indeed, Nettlefold and Stratford suggest one can read a spatial record of the history of rock climbing in its rock faces and representations of climbing spaces ${ }^{80}$. Yet, reading landscapes means attending as much to what is seen as to what is hidden, and, in so doing, tracing the discourses that perpetually shape landscapes ${ }^{81}$. Rock climbing is permeated with discourses of masculinist exploration of feminine nature, of mapping and assessing climbing spaces, of policing ethics and etiquette, and of rituals of inclusion/exclusion ${ }^{82}$. Such discourses frame the collective rock climbing identity but also fracture it among numerous sub-cultural identities in terms of climbing style, dedication, and even regional associations. So while Nettlefold and Stratford suggest climbers are an example of a "textual community" ${ }^{\prime 3}$ sharing the ability to read climbing landscapes as texts ${ }^{84}$, the rifts and subdivisions of the climbing community suggests it may be better considered as a collective of textual communities, which read and write the climbing landscape in differing, and sometimes conflicting, ways ${ }^{85}$.

In the production of representations of climbing spaces, rock climbing media (guidebooks, magazines, films, and websites) also circulate these various discourses and contests of climbing. Taylor provides a history of the development of climbing guidebooks, illustrating the tensions that surrounded the first endeavors $^{86}$. Borrowing from mountaineers, climbers of the 1950s began to map routes (create "topos") as a means to communicate directions to other climbers ${ }^{87}$. But perhaps more telling of the ideological implications of guidebooks, these first editions initiated selection processes as to which climbing styles, 
routes, and histories to include. Through omission, guidebook writers identified who should climb at particular areas, as some editions included only the most difficult climbs with language aimed at the most elite of climbers. The signs and codes of guidebooks thus produce a conceived space of climbing which suggest particular climbing bodies, climbing abilities, and socio-technical practices are appropriate for the performance of this spatial practice. In fact, most guidebooks are even colored-coded for quick identification of socio-technical practice (climbing style) - aid, traditional, sport, bouldering, mixed, ice offering prospective climbers a quick glance approach and informing any climber interested in a particular route the manner, in terms of gear and by extension mind-set, it should be approached. 


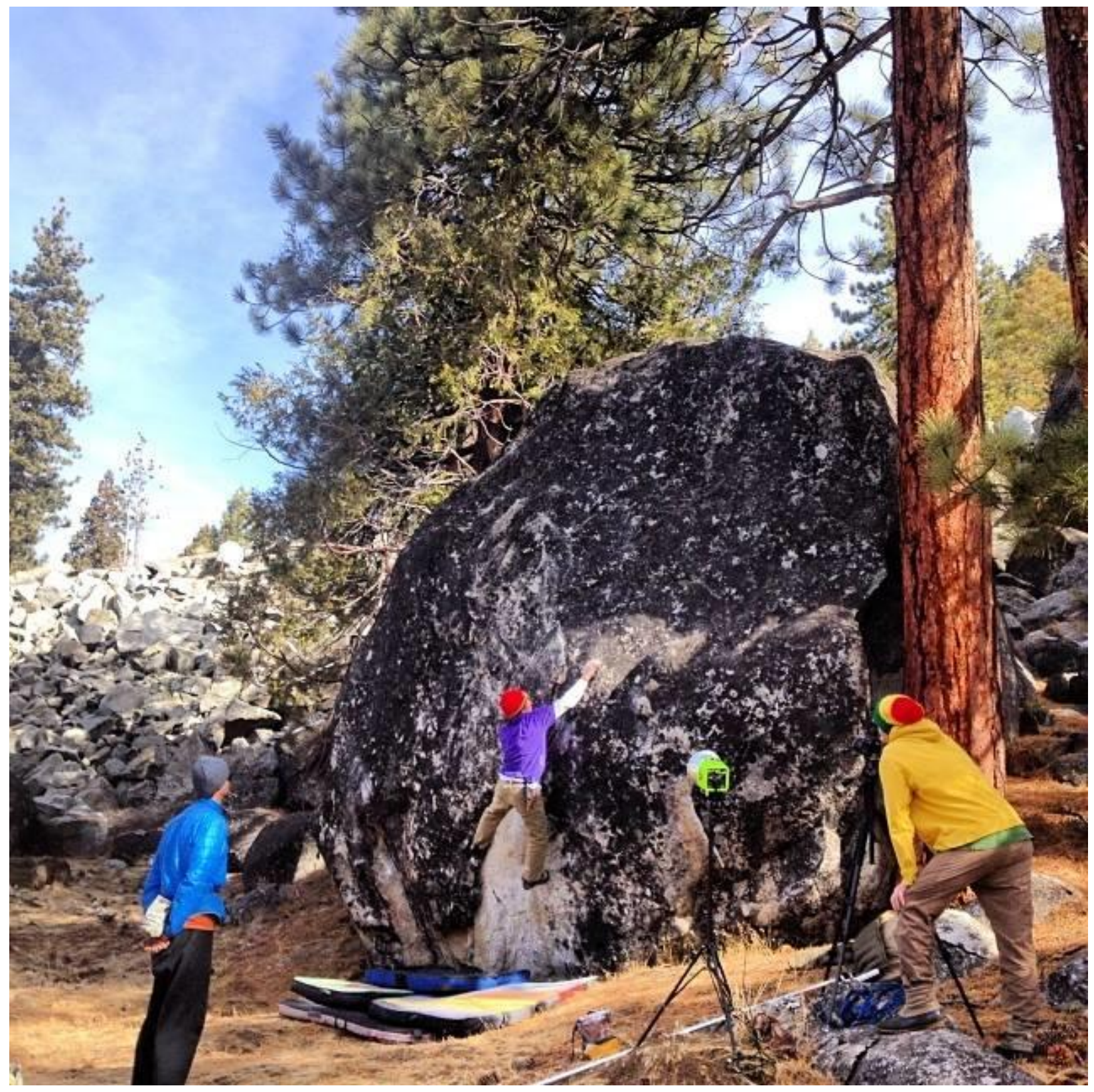

Figure 3 - Guidebook production. Photo courtesy of Darcy Harvey.

Further, a dialectic unfolds as guidebooks shape perception, "not between the climber and nature, but,

rather, between the individual and the community" ${ }^{\sharp 8}$. Parameters, limitations, and benchmarks established in guidebooks, and on websites, thus provide a measure for comparisons of skill and performance among individual climbers. Indeed, websites can be found that not only translate guidebook-style information to 
electronic and interactive resources, but websites have also been developed that enable individual climbers to record, track, and compare their climbing prowess. These representations of climbing spaces circulate ideologies of climbing space. Lefebvre states that ideologies do not produce space; it is social practice that produces space. As such, ideologies are in space, and moreover, ideologies are in representations of space and are enacted through spatial practice. Through the use of websites that compare climbers' abilities, representations of space reify ideologies when they are put into practice. Thus, in the (re)production of climbing space, that is, the continual co-production of the perceived/conceived/lived space of climbing, such representations of space (guidebooks, websites, films, and magazines) become doings.

\section{(Re)production and representations as doings}

Landscape is more than a text; it is a way of seeing ${ }^{89}$. As such, representations of climbing spaces inform how spaces are seen and thereby how they are approached and performed by the climbing body. Indeed, Heywood states,

a current guidebook is almost as important as a rope ... guidebooks contain enormous amounts of information, much of it in a codified, convention-governed form; with these descriptions the competent interpreter approaches the climb with a considerable amount of reliable, intersubjectively verified knowledge. Unpredictability is significantly reduced, while the climber's ability to objectify and control the climbing environment increases. ${ }^{90}$

Thus, routes, guidebooks, and climbing media are representations as doings when they influence the perceived space of the rock face and spatial practice of the climber. Representations, like ideology, have no inherent power; they circulate in the world only through their continual (re)production. This means they also always hold the potential to be challenged, adapted, adjusted, and dismantled. In the case of climbing, route grades are exemplary of representations as doings. In climbing a route, its grade is continually assessed. The grade of a newly developed route will be adjusted over time as climbers seek the path of least resistance up the rock face, which subsequent climbers follow, but also as frequent climbing polishes the holds, reducing their friction, the route can become more difficult which again changes its grade. Further, representations of climbing of space, such as route grades and what particular 
grades signify in terms of climbing ability, are put to use in the social spaces of climbing. Climbers use grades (and by association route names) to assess their own and others' climbing prowess. Such representations of space perpetuate ideologies of strength, agility, and skill. Indeed, it is through such representations of space that climbing space is put to use in the reproduction of climbing ideologies, as the rankings of the top climbers in the world are rationalized through association with the ability to climb particular grades.

The act of representing, argues Wylie, should be understood as "in and of the world of embodied practice and performance, rather than taking place outside of that world, or being anterior to, and determinative of, that world" $" 91$. The ways that climbing websites, as representations of space, act and are put to use in the world demonstrates their agency, their doing. While there are various types of websites associated with rock climbing, some function as a combination of guidebook (detailing route information) and diary (a record of climbing achievements - routes attempted, successfully climbed, and in what manner). These websites also have privacy settings, so users can share their activities with others (public, friends, or personal only). One such website is 8 a.nu, a Europe-based site with nearly 60,000 global members. The homepage ranks these members in terms of climbing prowess, which is assessed by a formula that assigns points to the grades of routes climbed, but also to the manner in which they are climbed (among other variables). For example, an "on-sight" receives the highest points for a route as it is completed on the first attempt without "beta" (helpful information about the route), while to "flash" a route - complete on the first attempt with "beta" - receives slightly fewer points, and completion after subsequent attempts earns fewer points still. So while the developers of the website note that the rankings should be considered "more like a fun motivator" than for competitive purposes, the rankings on the homepage, the ways 8a.nu is woven into other climbing media ("the Top-10 climbs, the last 12 months"), and the means through which climbers use these rankings as evidence of climbing prowess demonstrates the co-production of climbing space off the rock as its representations of space become doings and have agency in the world ${ }^{92}$. 
The agency of these representations of space was witnessed as one climber accused and confronted another for misrepresenting herself, via her climbing accomplishments, on 8a.nu. The incident in question was brought to the attention of other climbers one evening around a campfire. Having seen the latest updates on 8a.nu, one climber observed that a woman he had watched "redpoint" a route (complete ascent without rests, but after previous attempts) two days before recorded the climb as an "on-sight", thereby receiving much higher points. Several others confirmed his account, and the conversation then turned to lamenting such websites as ways in which misrepresentation of climbing ability is rampant and unpoliced, and thereby defiling the experience of climbing by adding competition. In other words, a criticism of such websites is that there is less truth in the representations of space such that the spatial practice of climbing is not communicated. The following day when he confronted her at a crag she was putting on her gear (harness, shoes, tying into the rope) in order to climb another route. While she denied his recounting, claiming that she knew how she had climbed that route, it became a topic of gossip that she later edited her logbook on 8a.nu to reflect a "redpoint" ascent rather than an "on-sight". In this case, the representations of climbing space that circulate far from the spatial practice of climbing were brought to bear in its perceived space. These representations of space have agency. They communicate climbing practice and ability far from the rock face. And, thus, when there is not agreement about the representation, they incite action.

This analysis of the production of climbing space should not be read as linear. Spatial practice does not set off a chain reaction that ultimately ends with representations of space; rather, it is a co-production of spatial relations. The performance of rock climbing is itself informed by representations of space, which are developed from the spatial practice of climbing, circulated among the climbing community, and put to use as ideologies. Lefebvre contends that the body does not simply produce space, but it also perceives the space it produces and the ways in which it is shaped through this interaction, and it responds to this. Social space is a triad - perceived, conceived, lived - produced from one another and in tandem. 


\section{Conclusion}

Rock climbing has been examined in the geographic literature through two perspectives - historically informed investigations of climbing landscapes as texts and relational materialist approaches to landscape-body interactions. This paper aims to work across both perspectives to better account for the ways the body is active in the production of climbing landscapes, but is also influenced by textual representations of landscape. Employing Henri Lefebvre's theories of the (social) production of (social) space affords such a goal. In asserting that space is produced and functions as a triad - perceived (spatial practice), conceived (representations of space), and lived (representational space) - Lefebvre moves beyond the notion of space as abstract and empty to an understanding of space as the result of human action. Yet, in so doing, he also articulates the role of the body as central to this process - as both producer and produced by space.

Embodied mobile practices have been given greater attention in geography in recent years. This is because they are exemplary of dialectical relations between space and body; they allow scholars to approach processes of co-constitution that are ongoing. Crouch states, “Articulating what landscape 'is', rather than how it emerges and happens feels very incomplete" ${ }^{\text {"93 }}$. It is, indeed, incomplete to reach an endpoint in the investigation of processes that involve active bodies and ever changing spaces. In responding to the performative turn in geography, this paper works to situate rock climbing among other studies of embodied mobile practice that illustrate that space (and landscape) are never complete when we attend to the role of the body in its co-production.

And, yet, the performative turn, in its investigations and illuminations of agency, materiality, and the more-than-representational has also left behind much of the critical cultural geography that was driven to deconstruct the power of representations ${ }^{94}$. In working with Lefebvre's notions of the production of social space, this paper aims to demonstrate the complementarity of the non-representational and the textual. In this sense, the analysis of rock climbing is only illustrative, not intended to be exclusive to the use of 
Lefebvre's theories. Rather, spatial trialectics reveal the relationality of, most importantly, the body to the more-than-representational communication and representational circulation of embodied mobile practices. The relationality of these bodily, material, gestural, verbal, textual, and informational aspects of the production of space is ongoing, always becoming, and surfacing in sometimes unpredictable ways that further entangle spatial practice with complexity that is lived and conceived, performed and read.

\section{Acknowledgements}

Much of the research that informed this paper was supported by a Dissertation Year Fellowship from Indiana University. A version of this paper was presented at the Adventure Research Symposium (2014) at Indiana University, where the participants were particularly generous and constructive with their feedback. The author also wishes to thank Professor Daniel Knudsen for comments on an earlier draft of this paper. The final version of this paper has been much improved thanks to the careful attention of two anonymous reviewers. Any final mistakes or shortcomings remain the responsibility of the author.

\section{Biographical Note}

Jillian Rickly is an Assistant Professor of Tourism Marketing and Management at The University of Nottingham. Her work weaves together environmental perceptions, identity and bio-politics, and performance theories to consider the relations between travel motivation and experience. She is a coauthor of the book Tourism, Performance and Place: A Geographic Perspective (2014).

\section{Notes}

1 K. Simonsen, 'Bodies, sensations, space and time: The contribution from Henri Lefebvre', Swedish Journal for Anthropology and Geography, 1, 2005, p. 2

2 See I. Borden, Skateboarding, space and the city - Architecture and the body (Oxford: Berg, 2001).

3 See J. Spinney, 'A place of sense: a kinaesthetic ethnography of cyclists on Mont Ventoux', Environment and Planning D: Society and Space, 24, 2006, pp. 709-732. 
4 See F.M. Wunderlich, 'Walking and rhythmicity: Sensing urban space', Journal of Urban Design, 13, 2008, pp. 125-139; J. Wylie, 'An essay on ascending Glastonbury Tor'. Geoforum, 22, 2002, pp. 441454; J. Wylie, 'A single day's walking: Narrating self and landscape on the South West Coast Path', Transactions of the Institute of British Geographers, 30, 2005, pp. 234-247; M. Michael, 'These boots were made for walking: mundane technology, the body and human-environment relations', in P. Macnaughten and J.Urry (eds) Bodies of nature (London: Sage, 2006), pp. 107-126.

5 See S.J. Saville, 'Playing with fear: Parkour and the mobility of emotion', Social \& Cultural Geography, 9, 2003, pp. 891-914; O. Mould, 'Parkour, the city, the event', Environment and Planning D: Society and Space, 27, 2009, pp. 738-750.

6 See P. Barratt, 'Vertical worlds: Technology, hybridity and the climbing body', Social \& Cultural Geography, 12, 2011, pp. 397-412; P. Barratt, "'My magic cam': A more-than-representational account of the climbing assemblage', Area, 44, 2012, pp. 46-53.

7 See P.A. Nettlefold and E. Stratford 'The production of climbing landscapes-as-texts', Australian Geographical Studies, 37, 1999, pp. 130-141; J.E. Taylor, Pilgrims of the vertical: Yosemite rock climbers \& nature at risk (Cambridge: Harvard University Press, 2010).

8 See R. Frison-Roche and S. Jouty. A history of mountain climbing. (Paris: Flammarion, 1996).

9 See L. Hamilton, 'Modern American rock climbing: Some aspects of social change', Pacific Sociological Review, 22, 1979, pp. 285-308; L. Tejada-Flores, Games climbers play. In Ascent, 1967, pp. 23-25; Nettlefold and Stratford, 'The production of climbing landscapes-as-texts'.

10 See N. Lewis, 'The climbing body, nature and the experience of modernity', Body \& Society, 6, 2000, pp. 58-80; N. Lewis, 'Sustainable adventure: Embodied experiences and ecological practices within British climbing', In Understanding Lifestyle Sports: Consumption, Identity and Difference, B. Wheaton, (ed.) (London: Routledge, 2004), pp. 70-93; J. Kiewa, 'Traditional climbing: Metaphor of resistance or metanarrative of oppression?', Leisure Studies, 21, 2002, pp. 134-161; L. Cailly, 'Climbing sites as counter-sites? Essay on neo-community forms and territorialisation processes at work in the practice of rock climbing', Journal of Alpine Research, 94, 2006, pp. 35-44; Taylor, Pilgrims of the vertical

11 See D. Mellor, American Rock: Region, Rock, and Culture in American Climbing, (Woodstock, VT: The Countryman Press, 2001).

12 See A. Bisharat, Sport Climbing: From Top Rope to Redpoint, Techniques for Climbing Success, (Seattle: The Mountaineers Books, 2009).

13 See C. Sharma, 'Foreword: The full circle', In Sport Climbing: From Top Rope to Redpoint, Techniques for Climbing Success (Seattle: The Mountaineers Books, 2009) p. 13; S.A. Ness, 'Bouldering in Yosemite: Emergent signs of place and landscape', American Anthropologist, 113, 2011, pp. 71-87; Barratt, 'Vertical worlds: Technology, hybridity and the climbing body';

14 See I. Heywood, I. 'Urgent dreams: Climbing, rationalization and ambivalence', Leisure Studies, 13, 1994, pp. 179-194; I. Heywood, 'Climbing monsters: Excess and restraint in contemporary rock climbing', Leisure Studies, 25, 2001, pp. 455-467; Kiewa, 'Traditional climbing: Metaphor of resistance or metanarrative of oppression?'. 
15 See A. D. Fave, M. Bassi and F. Massimini, 'Quality of experience and risk perception in high-altitude rock climbing', Journal of Applied Sport Psychology, 15, 2003, pp. 82-98; D.J. Llewellyn and X. Sanchez, 'Individual differences and risk taking in rock climbing', Psychology of Sport and Exercise, 9, 2008, pp. 413-426.

16 See D.G. Addiss, 'Mountaineering and rock-climbing injuries in U.S. national parks', Annals of Emergency Medicine, 18, 1989, pp. 975-993; F. Quaine, L. Vigouroux and L. Martin, 'Effect of simulated rock climbing finger postures on force sharing among the fingers', Clinical Biomechanics, 18, 2003, pp. 385-388; R. Forster, G. Penka, T. Bosl and V. R. Schoffl, 'Climber's back -- form and mobility of the thoracolumbar spine leading to postural adaptations in male high ability rock climbers', International Journal of Sports Medicine, 30, 2008, pp. 53-59.

17 See Nettlefold and Stratford, 'The production of climbing landscapes-as-texts'; Taylor, Pilgrims of the vertical; J. Taylor, 'Mapping adventure: A historical geography of Yosemite Valley climbing landscapes', Journal of Historical Geography, 32, 2006, pp. 190-219.

18 See Lewis, 'The climbing body, nature and the experience of modernity'; Lewis, 'Sustainable adventure: Embodied experiences and ecological practices within British climbing'; P. Rossiter, 'On humans, nature, and other nonhumans', Space and Culture, 10, 2007, pp. 292-305; S.A. Ness, 'Bouldering in Yosemite: Emergent signs of place and landscape'; Barratt, 'Vertical worlds'; Barratt, "'My magic cam"”.

19 H. Lefebvre, The production of space (Oxford: Blackwell Publishing, 1991), p. 61.

20 Lefebvre, The production of space, p. 195; K. Simonsen, 'Bodies, sensations, space and time'.

21 V. Miller, 'The unmappable: Vagueness and spatial experience', Space and Culture, 9, 2006, pp. 453467.

22 K. Simonsen, 'Bodies, sensations, space and time'.

23 K. Simonsen, 'Bodies, sensations, space and time', p. 11.

24 See Author, 2012; 2016. Lifestyle climbers are full-time rock climbers who travel in pursuit of the sport year-round. They seek temporary and/or online employment and utilize a personal vehicle (car, van, or RV) as a mobile adobe

25 D. Mellor, American Rock: Region, Rock, and Culture in American Climbing, (Woodstock, VT, The Countryman Press: 2001).

26 Victory Productions, Red River Ruckus, 2005.

27 B. Erikson, 'Style matters: Explorations of bodies, whiteness, and identity in rock climbing', Sociology of Sport Journal, 22, 2, 2005, pp. 373-396.

28 See Barratt, 'Vertical worlds'; S. Eden, S. \& P. Barratt, 'Outdoors versus indoors? Angling ponds, climbing walls and changing expectations of environmental issues', Area, 42, 2010, pp. 487-493.

29 Lefebvre, The production of space, p. 33. 
30 Lefebvre, The production of space, p. 38.

31 Lefebvre, The production of space, p. 39.

32 Lefebvre, The production of space, p. 39.

33 K. Simonsen, 'Bodies, sensations, space and time', p.7.

34 K. Simonsen, 'Bodies, sensations, space and time'.

35 Lefebvre, The production of space, p. 170.

36 K. Simonsen, 'Bodies, sensations, space and time'; K. Simonsen, 'Place as encounters: Practice, conjunction, and co-existence', in J.O. Baerenholdt and B. Granas (eds), Mobility and place: Enacting Northern European peripheries (Aldershot, UK: Ashgate Publishing, 2008) pp. 13-26.

37 P. Leavy, P. 2008. 'Performance-based emergent methods', in Handbook of emergent methods S. N. Hesse-Biber and P. Leavy (eds.), (New York: The Guilford Press, 2008) p. 346.

38 M. Merleau-Ponty, Maurice Merleau-Ponty: basic writings (New York,: Routledge, 2004) p. 93.

39 Lewis, 'The climbing body', p. 59.

40 Nettlefold and Stratford, 'The production of climbing landscapes-as-texts'; Taylor, Pilgrims of the vertical; Taylor, 'Mapping adventure'; Barratt, 'Vertical worlds'; Ness, 'Bouldering in Yosemite'.

41 Rossiter, 'On humans, nature, and other nonhumans'.

42 Rossiter, 'On humans, nature, and other nonhumans', p. 298; See also Barratt, 'Vertical worlds'; Barratt, "'My magic cam"'; Ness, 'Bouldering in Yosemite'.

43 Lewis, 'The climbing body', p. 74.

44 Lewis, 'The climbing body'.

45 Simonsen, 'Bodies, sensations, space and time', p.10-11

46 Simonsen, 'Bodies, sensations, space and time', p.10-11

47 Lefebvre, The production of space, p. 195.

48 See also Heywood, 'Urgent dreams'.

49 Lewis, 'The Climbing Body', p. 71.

50 Quaine, Vigouroux, and Martin, 'Effect of simulated rock climbing'.

51 Förster, Penka, Bösl, Schöffle, 'Climber's back' 
52 Lewis, 'The climbing body', p. 75. See also Rossiter, 'On humans, nature, and other nonhumans'; Barratt, 'Vertical worlds'; Barratt, “'My magic cam"'.

53 Sharma, 'Foreword: The full circle'.

54 Rossiter, 'On humans, nature, and other nonhumans'

55 Barratt, 'Vertical worlds'; Barratt, “'My magic cam"'

56 Barratt, 'Vertical worlds'; Barratt, “'My magic cam"'

57 Barratt, 'Vertical worlds', p. 403.

58 R.B. Killian, G.S. Nishimoto, and J.C. Page, 'Foot and ankle injuries related to rock climbing. The role of footwear', Journal of the American Podiatric Medical Association, 88, 8, 1998, pp. 365-374; M.D. Rooks, "Rock climbing injuries." Sports medicine, 23, 4, 1997, pp. 261-270.

59 Barratt, 'Vertical worlds'; Barratt, “'My magic cam"”

60 Lefebvre, The production of space, p. 210

61 See Alex Honnold, professional climber, as interviewed in The Atlantic, "The Risky Appeal of Free Climbing", November, 2015, Accessed at: http://www.theatlantic.com/magazine/archive/2015/11/thecliffhanger/407824/

62 T. Cresswell and P. Merriman, 'Introduction: Geographies of mobilities - Practices, spaces, subjects', in Geographies of mobilities - Practices, spaces, subjects, T. Cresswell and P. Merriman (eds.), (Burlington, VT: Ashgate, 2011), p. 5.

63 Simonsen, 'Bodies, sensations, space and time', p.6; P. Bourdieu, P. Outline of a theory of practice, (Cambridge: Cambridge University Press, 1977); P. Bourdieu The logic of practice (Cambridge: Polity Press, 1990).

64 Ness, 'Bouldering in Yosemite', p. 75.

65 H. Lorimer, 'Cultural geography: the busyness of being "more-than-representational"', Progress in Human Geography, 29, 2005, pp. 83-94.

66 Lefebvre, The production of space, p. 174.

67 Lorimer, 'Cultural geography'.

68 Lewis, 'The climbing body'.

69 K. Somdahl-Sands, 'Non-Representational theory for the uninitiated: Come JUMP with me!', Geography Compass, 7, 2013, pp. 1-6.

70 Lefebvre, The production of space.

71 E. Goffman, Behaviour in public places: Notes on the social organization and gathering (New York, 
The Free Press: 1963); E. Goffman, The presentation of self in everyday life (Harmondsworth, Penguin Books: 1990 [1950]).

72 Lefebvre, The production of space, p. 213-216.

73 Lefebvre, The production of space, p. 215.

74 Nettlefold and Stratford, 'The production of climbing landscapes-as-texts'; Taylor, 'Mapping adventure'; Taylor, Pilgrims of the vertical.

75 Rossiter, 'On humans, nature, and other nonhumans'.

76 See Taylor, 'Mapping adventure'.

77 Nettlefold and Stratford, 'The production of climbing landscapes-as-texts', p. 137.

78 See Taylor, 'Mapping adventure', p. 194-195 for further explanation and examples.

79 Lefebvre, The production of space, p. 17.

80 Nettlefold and Stratford, 'The production of climbing landscapes-as-texts'.

81 R.H. Schein, 'The place of landscape: A conceptual framework for interpreting an American scene', Annals of the Association of American Geographers 87: 1997, pp. 660-680.

82 Kiewa, 'Traditional climbing'; L. Cailly, 'Climbing sites as counter-sites? Essay on neo-community forms and territorialisation processes at work in the practice of rock climbing', Journal of Alpine Research, 94, 2006, pp. 35-44; V. Robinson, Everyday masculinities and extreme sport: Male identity and rock climbing (Oxford: Berg, 2008); R. E. Dilley and S. J. Scraton, 'Women, climbing, and serious leisure', Leisure Studies, 29, 2010, pp. 125-141.

83 J. Duncan and N. Duncan, '(Re)reading the landscape', Environment and Planning D: Society and Space, 6, 1988, p. 120.

84 Nettlefold and Stratford, 'The production of climbing landscapes-as-texts'.

85 See Kiewa, 'Traditional climbing'; L. Cailly, 'Climbing sites as counter-sites?'; Taylor, Pilgrims of the vertical; T. Williams P. Donnelly, 'Subcultural production, reproduction, and transformation in climbing', International Review for the Sociology of Sport, 20(1), 1985, pp. 3-17; P. Donnelly, 'The great divide: sport vs. adventure climbing', in R.E. Rinehart and S. Syndor (eds) To the extreme: Alternative sports, inside and out (Albany: State University of New York Press: 2003), pp. 291-304.

86 Taylor, 'Mapping adventure'; Taylor, Pilgrims of the vertical.

87 Taylor, 'Mapping adventure'; Taylor, Pilgrims of the vertical.

88 Taylor, 'Mapping adventure', p. 203.

89 D. Cosgrove, Social formation and symbolic landscape (Madison: University of Wisconsin Press, 1988). 
90 Heywood, 'Urgent dreams', p. 186.

91 J. Wylie, Landscape, (London: Routledge, 2007), p. 164; See also J.D. Dewsbury, P. Harrison, M. Rose, \& J. Wylie 'Enacting geographies' Geoforum, 33(4), 2002, p. 437-440.

92 http://www.8a.nu/. Accessed 13 January 2016.

93 D. Crouch, 'Flirting with space: thinking landscape relationally', Cultural Geographies, 17, 2010, p. 6.

94 See T. Cresswell, 'Review Essay: Nonrepresentational theory and me: notes of an interested sceptic', Environment and Planning D: Society and Space, 30(1), 2012, pp. 96-105. 